\title{
Anticancer effects of the MHY218 novel hydroxamic acid-derived histone deacetylase inhibitor in human ovarian cancer cells
}

\author{
HEUI SOOK JEON ${ }^{1 *}$, MEE YOUNG AHN ${ }^{1 *}$, JI HYE PARK ${ }^{1}$, TAE HYUNG KIM ${ }^{1,2}$, PUSOON CHUN ${ }^{1}$, \\ WON HEE KIM ${ }^{1}$, JUNGSU KIM ${ }^{1}$, HYUNG RYONG MOON ${ }^{1}$, JEE H. JUNG ${ }^{1,2}$ and HYUNG SIK KIM ${ }^{1,2}$ \\ ${ }^{1}$ College of Pharmacy; ${ }^{2}$ MRC center, College of Pharmacy, Pusan National University, \\ San 30, Jangjeon-dong, Geumjeong-gu, Busan 609-735, South Korea
}

Received April 6, 2010; Accepted May 26, 2010

DOI: 10.3892/ijo_00000690

\begin{abstract}
To investigate the anticancer effects of the novel hydroxamic acid-derived histone deacetylase (HDAC) inhibitor MHY218, its efficacy was compared to that of suberoylanilide hydroxamic acid (SAHA) in human ovarian cancer cells. The anticancer effects of MHY218 on cell viability, cell cycle regulation and apoptosis were investigated. In addition, MHY218 or SAHA was administered for 28 days in a tumor carcinomatosis model with SKOV-3 cells. MHY218 significantly reduced the expression of HDAC4 and HDAC7 in SKOV-3 cells. Similarly, MHY218 also inhibited total HDAC, HDAC1, HDAC4 and HDAC7 enzyme activity in a concentration-dependent manner. The anticancer effect of MHY218 ( $\left.\mathrm{IC}_{50}, 3.2 \mu \mathrm{M}\right)$ was more potent than SAHA $\left(\mathrm{IC}_{50}, 3.9 \mu \mathrm{M}\right)$ in suppressing the SKOV-3 cell viability. Moreover, MHY218 markedly increased expression of $\mathrm{p} 21^{\mathrm{WAF} / \mathrm{CIP} 1}$, which acts as a cell cycle inhibitor. Cell cycle analysis showed that the high dose $(5 \mu \mathrm{M})$ of MHY218 significantly increased the proportion of cells in the G2/M phase. In particular, MHY218 and SAHA significantly increased the sub-G1 population and the number of TUNELpositive apoptotic cells compared with those in the untreated control. These results were confirmed by analysis of polyADP ribose polymerase (PARP), where MHY218 and SAHA increased the level of an $85-\mathrm{kDa}$ fragment resulting from PARP cleavage as well as caspase- 3 activity. Likewise, MHY218-induced apoptosis through caspase-3 activation was confirmed by the increase in the release of cytochrome $c$ and $\mathrm{Bax} / \mathrm{Bcl}-2$ ratio. In an in vivo tumor carcinomatosis model, the growth of transplanted SKOV-3 cells was inhibited by $71 \%$ after treatment with MHY218 $(10 \mathrm{mg} / \mathrm{kg})$, whereas SAHA $(25 \mathrm{mg} / \mathrm{kg})$ suppressed growth by $48 \%$. These results
\end{abstract}

Correspondence to: Professor Hyung Sik Kim, College of Pharmacy, Pusan National University, San 30, Jangjeon-dong, Geumjeong-gu, Busan 609-735, South Korea

E-mail: hkims@pusan.ac.kr

*Contributed equally

Key words: hydroxamic acid-derived histone deacetylase, suberoylanilide hydroxamic acid, MHY218, ovarian cancer, apoptosis indicate that MHY218 is a potent HDAC inhibitor that targets regulating multiple aspects of cancer cell death and might have preclinical value in ovarian cancer chemotherapy, warranting further investigation.

\section{Introduction}

Ovarian cancer had an incidence of 21,650 new cancer cases and accounted for 15,520 deaths in 2008 in the USA (1). Despite considerable efforts to improve early detection and advances in chemotherapy, the high mortality rate of ovarian cancer has markedly increased worldwide. In addition, metastasis remains a major challenge in the clinical management of ovarian cancer (2). There is an urgent need to develop new strategies to treat ovarian cancer, the most deadly gynecologic malignancy.

Histone deacetylase (HDAC) inhibitors are a promising new class of anticancer agents that act through a variety of mechanisms, including growth inhibition of cancer cells and induction of cell cycle arrest, differentiation and apoptosis in cancer cells (3-5). The precise mechanisms for the anticancer activities of HDAC inhibitors may also involve histone acetylation and deacetylation of amino groups of lysine residues present in the tail of the core histones (6). Deacetylation of histone protein is a major step in the epigenetic regulation of cancer-related gene expression, and alters the structure of chromatin $(7,8)$.

Based on these findings, HDACs have become an attractive target for cancer therapy, and efforts to develop HDAC inhibitors as anticancer drugs have increased $(9,10)$. HDAC inhibitors can be divided into 4 classes including hydroxamates, cyclic peptides, aliphatic acids and benzamides (6). Among clinically relevant HDAC inhibitors, suberoylanilide hydroxamic acid (SAHA) is the first potent inhibitor of HDACs to be approved for clinical use in cancer patients with T-cell lymphoma $(11,12)$. Although the mechanisms of SAHA activity are not completely understood, it is clear that SAHA induces cell death of transformed cells by altering the transcription of expressed genes, causing growth arrest and promoting caspase transcription of expressed genes, and promoting caspase-dependent apoptotic cell death (13-15).

Recently, the anticancer effects of natural and synthetic HDAC inhibitors have been studied against various cancer cell lines and in vivo animal models (16-19). Among them, 
the newly designed hydroxamic acid-based HDAC inhibitor is an attractive anticancer agent (12). In this study, MHY218 [ $\mathrm{N}^{1}$-hydroxy-N $\mathrm{N}^{8}$-(4-phenoxyphenyl)octanedianide] was synthesized and it was a novel hydroxamic acid-based HDAC inhibitor, possessing potent inhibitory activity against HDAC enzyme (Fig. 1A).

In the present study, the antitumor efficacy of MHY218 compared with that of SAHA was evaluated in ovarian cancer models in vitro and in vivo. The effects of MHY218 on the expression of various HDAC isoforms and on the growth of ovarian cancer cells were examined. In addition, the effects of MHY218 on cell cycle progression and apoptosis were investigated, and possible molecular mechanisms for these effects were explored. The effect of MHY218 on tumor growth in a carcinomatosis model was also examined, confirming the functional significance of these MHY218-mediated effects.

\section{Materials and methods}

Chemicals. Unless otherwise stated, SAHA [cyclo(N-Omethyl-L-tryptophanyl-L-isoleucinyl-D-pipecolinyl-L-2amino-8-oxodecanoyl)] and all chemicals were purchased from Sigma-Aldrich (St. Louis, MO, USA). The new HDAC inhibitor MHY218, was kindly provided by Professor Hyung Ryong Moon (Pusan National University, Busan, Korea). Trichostatin A (TsA), SAHA and MHY218 were dissolved in sterile dimethyl sulfoxide (DMSO) to generate $10 \mathrm{mM}$ stock solutions. The solutions were stored at $-80^{\circ} \mathrm{C}$. Subsequent dilutions were made in RPMI-1640 (Gibco, Rockville, MD, USA).

Cell line and culture media. The SKOV-3 human ovarian cancer cell line was purchased from the American Type Culture Collection (Manassas, VA, USA). The cells were maintained as monolayers at $37^{\circ} \mathrm{C}$ in an atmosphere containing 5\% $\mathrm{CO}_{2}$ /air in RPMI-1640 (Gibco) containing $10 \%$ heat-inactivated fetal bovine serum (FBS, Gibco), $1.25 \mathrm{mM}$ HEPES (Gibco) and $100 \mathrm{U} / \mathrm{ml}$ penicillin/streptomycin (Gibco). For the MHY218 treatment, the cells were plated for $48 \mathrm{~h}$ in RPMI-1640 containing 10\% FBS. The medium was then changed to RPMI-1640 containing 5\% charcoal/dextran-treated FBS (CD-FBS) with various concentrations of MHY218.

HDAC activity assay. The HDAC enzyme activity was performed using a fluorogenic HDAC assay kit purchased from BPS Bioscience (San Diego, CA, USA) according to the manufacturer's instructions. Briefly, HDAC enzymes were incubated with vehicle or various concentrations of TsA, SAHA, or MHY 218 at $37^{\circ} \mathrm{C}$ for $30 \mathrm{~min}$ in the presence of an HDAC fluorimetric substrate. The HDAC assay developer (which produces a fluorophore in reaction mixture) was added, and the fluorescence was measured using VICTOR 3 (Perkin-Elmer, Waltham, MA, USA) with excitation at $360 \mathrm{~nm}$ and emission at $460 \mathrm{~nm}$. The measured activities were substracted by calculated using GraphPad Prism (GraphPad software, San Diego, CA, USA).

Detection of cytotoxicity. Cell growth was quantified using 3-(4,5-dimethylthiazol-2-yl)-2,5-diphenyltetrazolium bromide
A<smiles>O=C(O)CCCCCCC(=O)Nc1ccccc1</smiles>

B

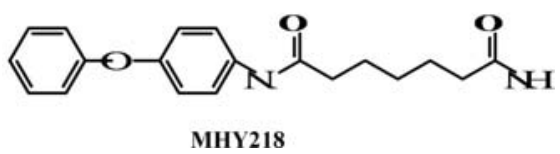

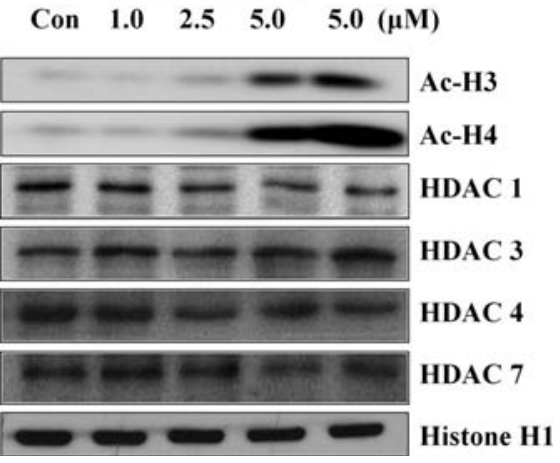

Figure 1. Effects of MHY218 on the expression of acetylated histone protein and HDAC in SKOV-3 cells. (A) Chemical structures of HDAC inhibitors, MHY218 and SAHA (B) SKOV-3 cells were treated with MHY218 and SAHA at the indicated concentrations for $48 \mathrm{~h}$. Total cell lysates were prepared and the protein was subjected to SDS-PAGE followed by Western blot analysis. Control cells were treated with vehicle alone. Representative bands from three independent experiments are shown.

(MTT, $5 \mathrm{mg} / \mathrm{ml}$ ) dissolved in phosphate-buffered saline (PBS). The cultures were initiated in 96-well plates at a density of $1 \times 10^{4}$ cells per well. Cells were allowed to attach for $48 \mathrm{~h}$ before exposure to SAHA and MHY218. At the end of the treatment period, $15 \mu \mathrm{l}$ of MTT reagent were added to each well. After $4 \mathrm{~h}$ incubation at $37^{\circ} \mathrm{C}$, the supernatant was aspirated, and formazan crystals were dissolved in $100 \mu 1$ DMSO at $37^{\circ} \mathrm{C}$ for 10 min with gentle agitation. The absorbance per well was measured at $540 \mathrm{~nm}$ with a VERSA Max micro-plate reader (Molecular Devices Corp., Sunnyvale, CA, USA).

Western blot analysis. The cells were washed twice with PBS, suspended in lysis buffer [50 mM Tris (pH 8.0), $150 \mathrm{mM}$ $\mathrm{NaCl}, 0.1 \%$ SDS, $0.5 \%$ sodium deoxycholate, $1 \%$ NP-40, $100 \mu \mathrm{g} / \mathrm{ml}$ phenylmethylsulfonyl fluoride, $2 \mu \mathrm{g} / \mathrm{ml}$ aprotinin, $1 \mu \mathrm{g} / \mathrm{ml}$ pepstatin, and $10 \mu \mathrm{g} / \mathrm{ml}$ leupeptin], and placed on ice for $30 \mathrm{~min}$. The suspension was centrifuged at 15,000 $\mathrm{x}$ g for $15 \mathrm{~min}$ at $4^{\circ} \mathrm{C}$, and the supernatant was collected. The protein concentrations were quantified using the Bio-Rad protein assay reagent (Bio-Rad Laboratories, Hercules, CA, USA) according to the manufacturer's protocol. The protein was resolved on $8-12 \%$ SDS-polyacrylamide gel, transferred to polyvinylidene difluoride (PVDF) membrane (NEN Life Science, Boston, MA, USA) and probed with antibodies against acetylated $\mathrm{H} 3$ and $\mathrm{H} 4$ (Upstate, Lake Placid, NY, USA), histone H1 (Upstate), HDAC1 (Cell Signaling, MA, USA), HDAC2 (Cell Signaling), HDAC3 (Cell Signaling), HDAC4 (Cell Signaling), HDAC7 (Cell Signaling), $\mathrm{p} 21^{\mathrm{WAF} 1 / \mathrm{CIP} 1}$ (Cell Signaling) or B-actin antibody (Sigma). The 

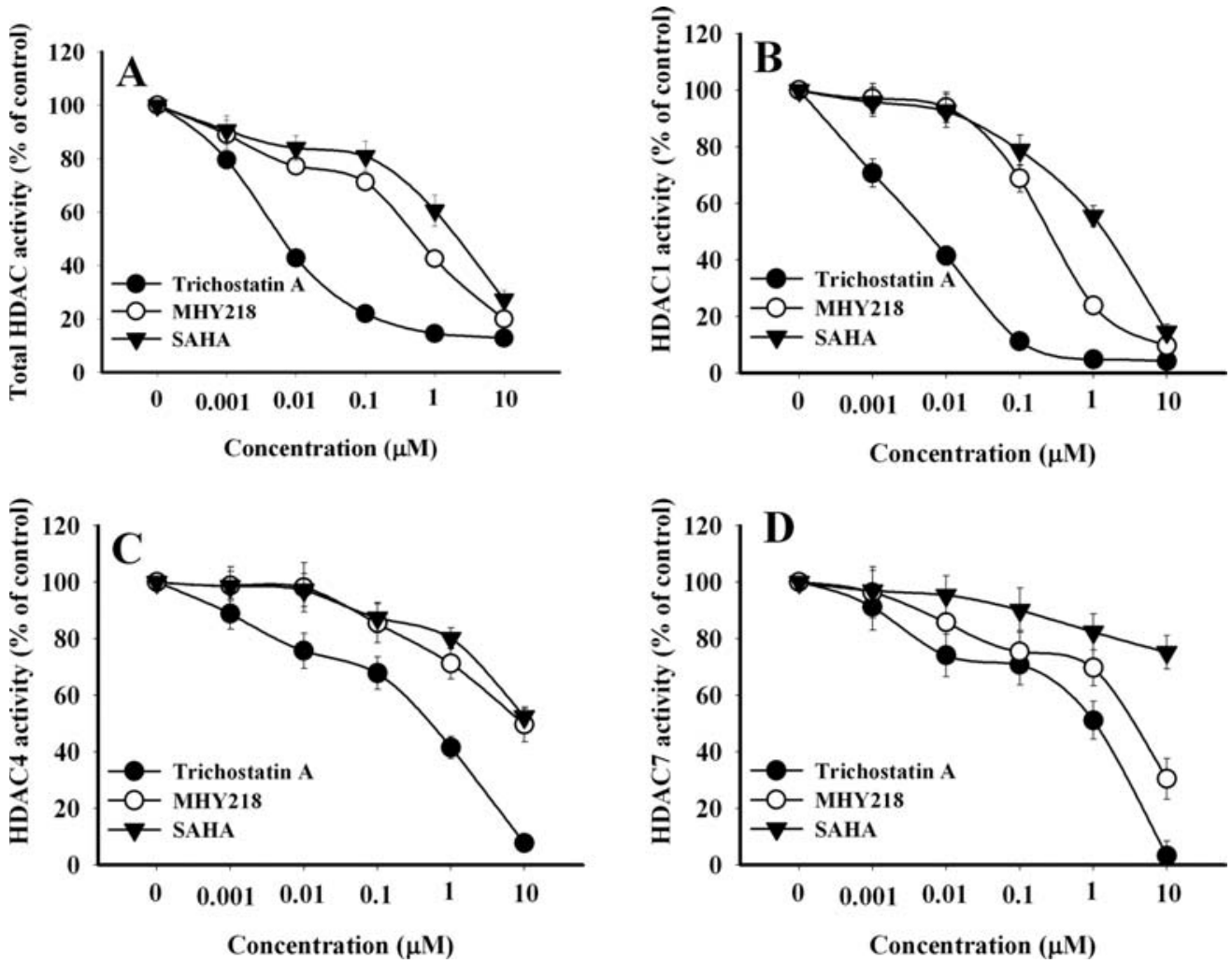

Figure 2. Effect of MHY218 on HDAC enzyme activity. The HDAC enzyme activity was measured in nuclear extract from HeLa cell using a fluorometric HDAC activity assay kit. Data are expressed as mean \pm SEM of three independent experiments.

blots were developed using an enhanced chemiluminescence (ECL) kit (Amersham, Cardiff, UK).

Cell cycle and sub-G1 analysis. Cell cycle and sub-G1 distribution were determined by staining DNA with propidium iodide (PI). SKOV-3 cells were treated with the indicated concentrations of MHY218 $(0,1,2.5$ or $5 \mu \mathrm{M})$ and SAHA $(5 \mu \mathrm{M})$ for $24 \mathrm{~h}$. Cells were harvested in trypsin, fixed in $70 \%$ ethanol for $1 \mathrm{~h}$, washed twice with PBS and resuspended in the PI/RNase A solution for $30 \mathrm{~min}$. The DNA content was detected by a FACScan flow cytometry (BectonDickinson, San Jose, CA, USA). Data analysis was performed with CellQuest software (BD Biosciences).

TUNEL assay. SKOV-3 cells were grown on coverslips at a density of $5 \times 10^{4}$ cells per well in a 24 -well plate. After the MHY218 and SAHA treatment for $48 \mathrm{~h}$, apoptosis was detected using an ApopTag fluorescein in situ apoptosis detection kit (Chemicon International, Temecula, CA, USA) and PI staining. The cells were observed using confocal laser scanning microscopy (TCS SP2, Leica, Wetzler, Germany). To determine TUNEL expression, the number of apoptotic events was counted in ten random fields and divided that number by the total number of cells per field.

Caspase activity assay. The cultures were initiated in 6-well plates at a density of $1 \times 10^{5}$ cells per well. The cells were allowed to attach for $48 \mathrm{~h}$ and then exposed to MHY218 or SAHA for $48 \mathrm{~h}$. The caspase- 3 and caspase- 8 activities in the cell lysate were determined using colorimetric assay kits (Biovision, CA, USA). Cell lysate $(50 \mu \mathrm{l})$ (cytosolic extracts, $100 \mu \mathrm{g}$ ) was incubated in $50 \mu \mathrm{l}$ of $2 \mathrm{X}$ reaction buffer and $2 \mu \mathrm{l}$ of the substrates (DEVD-pNA for caspase-3 and IETD-pNA for caspase-8) at $37^{\circ} \mathrm{C}$ for $2 \mathrm{~h}$. After incubation, the chromophores were quantified spectrophotometrically at a wavelength of $405 \mathrm{~nm}(20)$.

In vivo carcinomatosis model. Six-week-old female nude mice (BALB-c nu/nu, Charles River Lab. Inc., Wilmington, MA, USA) were housed under controlled temperature $\left(22 \pm 2^{\circ} \mathrm{C}\right)$ and lighting $(12 \mathrm{~h}$ light/dark cycle $)$ conditions in filtered-air laminar-flow cabinets and manipulated using aseptic procedures. Prior to experimentation, all animal procedures were approved by the Experimental Animal Care Commission, Pusan National University (Busan, Korea). A cell suspension of SKOV-3 cells was injected intraperitoneally (i.p.) into 5 nude mice $\left(1 \times 10^{7}\right.$ cells per animal) in each experimental group. The treatment regimens began the day after tumor inoculation and continued for 28 days. This model corresponds to remission cases after the primary treatment of patients with stage III ovarian cancer (21). MHY218 (10 mg/kg) and SAHA $(25 \mathrm{mg} / \mathrm{kg})$ were administered i.p. with twice a week to the nude mice for 28 days, and the control mice were administered DMSO in the same manner. The body weights were recorded before dosing. The mice were sacrificed at the end of the treatment period. The tumor tissue was collected, weighed and frozen in liquid nitrogen, and stored at $-80^{\circ} \mathrm{C}$ until needed.

Statistical analysis. All data are represented as the mean \pm SEM. A paired Student's t-test was used to determine the statistical significance. ${ }^{*} \mathrm{p}<0.05$ or ${ }^{* *} \mathrm{p}<0.01$ were considered significant. 

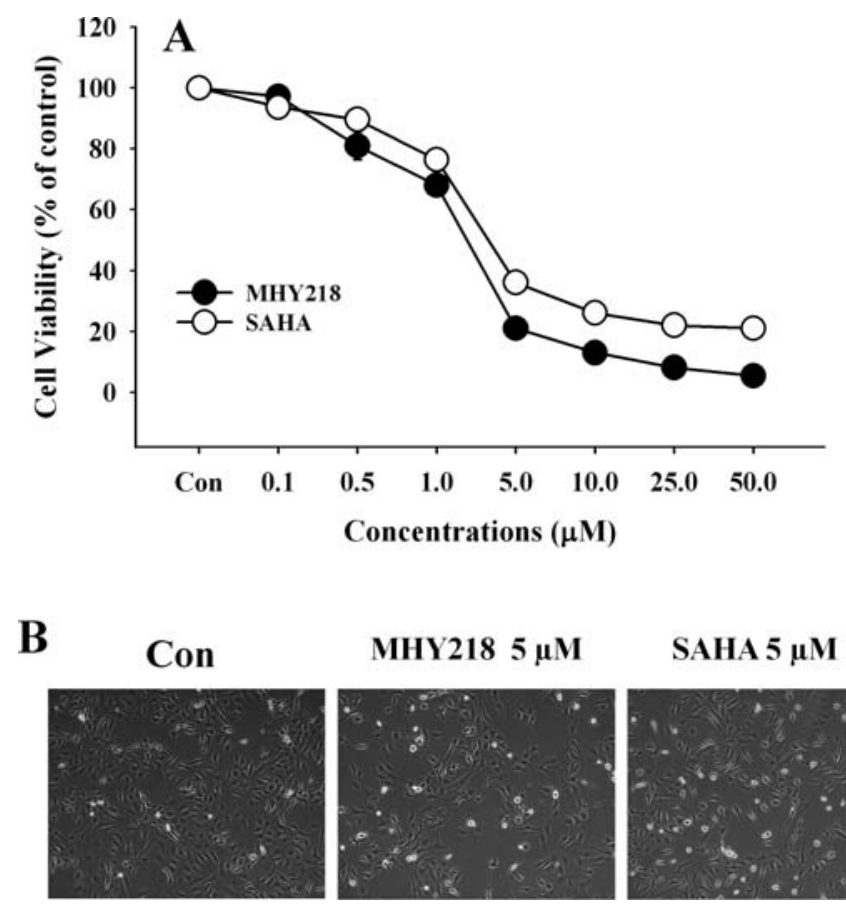

SAHA $5 \mu$ M

Figure 3. Effect of MHY218 on cytotoxicity of SKOV-3 cells. SKOV-3 cells were treated with the indicated concentrations of MHY218 and SAHA for 48 h. (A) Data are expressed as mean \pm SEM. (B) Morphologic changes in SKOV-3 cells treated with MHY218 and SAHA. SKOV-3 cells treated with vehicle control (left), $5 \mu \mathrm{M}$ MHY218 (middle), or $5 \mu \mathrm{M} \mathrm{SAHA}$ (right) for $24 \mathrm{~h}$. Original magnification, $\mathrm{x} 100$.

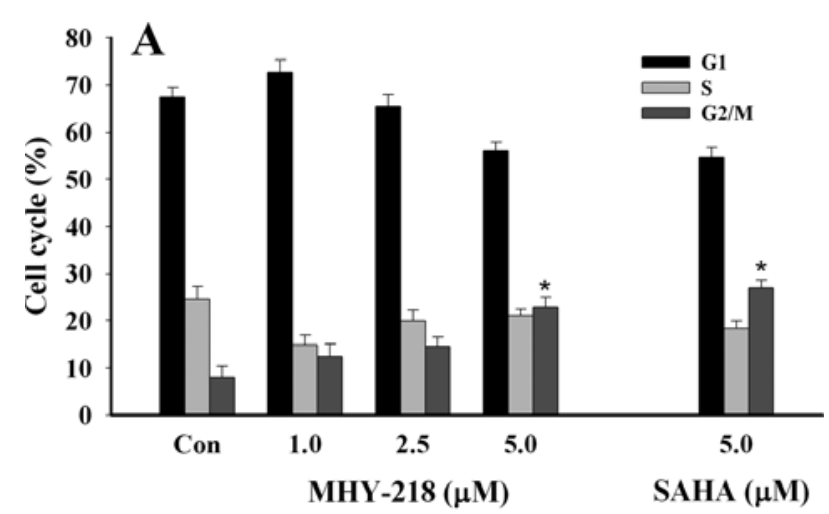

B

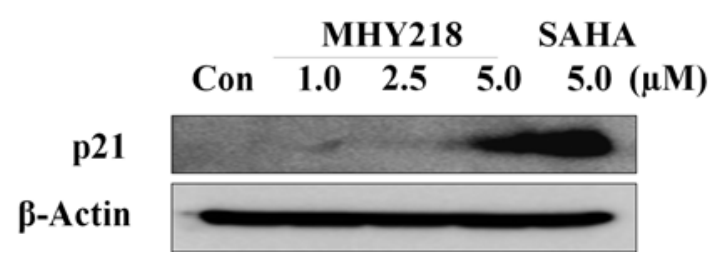

Figure 4. Effect of SAHA and MHY218 on cell cycle of SKOV-3 cells as analyzed by flow cytometry. (A) SKOV-3 cells were treated with the indicated concentrations of MHY218 for $24 \mathrm{~h}$. Cells were stained with propidium iodine (PI) and subjected to flow cytometry analysis to determine the cell distribution in each phase of the cell cycle. The data are expressed as the mean \pm SEM of two independent experiments. " $\mathrm{p}<0.05$ by an ANOVA test compared with the control group. (B) Effect of MHY218 on the expression of $\mathrm{p} 21^{\mathrm{WAF} / \mathrm{CIP} 1}$ in SKOV-3 cells. Cells were treated with MHY218 for $24 \mathrm{~h}$. Total cell lysates were prepared and the protein was subjected to SDSPAGE, Western blot analysis and chemiluminescent detection. Western blot analysis was performed with antibodies to $\mathrm{p} 21^{\mathrm{WAF} / / \mathrm{CIP} 1}$ and $\mathrm{B}$-actin. The protein levels were normalized to $B$-actin levels. Representative bands of three independent experiments are shown.

\section{Results}

MHY218 inhibited HDAC expression and enzyme activity. The effect of MHY218 on the level of acetylated histone protein in the SKOV-3 cells was examined by Western blot analysis using the specific antibodies against acetylated $\mathrm{H} 3$ and H4. MHY218 and SAHA treatment at $5 \mu \mathrm{M}$ significantly increased the levels of acetylated $\mathrm{H} 3$ and $\mathrm{H} 4$ in the SKOV-3 cells (Fig. 1B). Western blotting using specific HDAC subtype antibodies was performed to further analyze the expression of the specific HDAC subtypes after MHY218 treatment. The levels of HDAC4 and HDAC7 protein expression were down-regulated by MHY218 treatment in SKOV-3 cells (Fig. 1B).

The effect of MHY218 and SAHA on total HDAC, HDAC1, HDAC4 and HDAC7 enzyme activity was next compared. As shown in Fig. 2A, MHY218 potently inhibited the total HDAC enzyme activity, and the $\mathrm{IC}_{50}$ value $(0.468 \mu \mathrm{M})$ of MHY218 was lower than that of SAHA. MHY218 also markedly inhibited HDAC1 and HDAC7 enzyme activity and the $\mathrm{IC}_{50}$ values of MHY218 were lower than those of SAHA used as a positive control (Fig. 2B and D).

MHY218 inhibited the proliferation of SKOV-3 cells. The antiproliferative effect of MHY218 on ovarian cancer cells was determined by MTT assay, and the results are shown in Fig. 3A. MHY218 inhibited the proliferation of SKOV-3 cells in a dose-dependent manner, and a significant decrease in cell proliferation was observed at the lowest concentrations $(1-5 \mu \mathrm{M})$ after $48 \mathrm{~h}$ treatment. From these results, the $\mathrm{IC}_{50}$ values of MHY218 and SAHA were calculated as 3.2 and $3.9 \mu \mathrm{M}$, respectively. It is noteworthy 

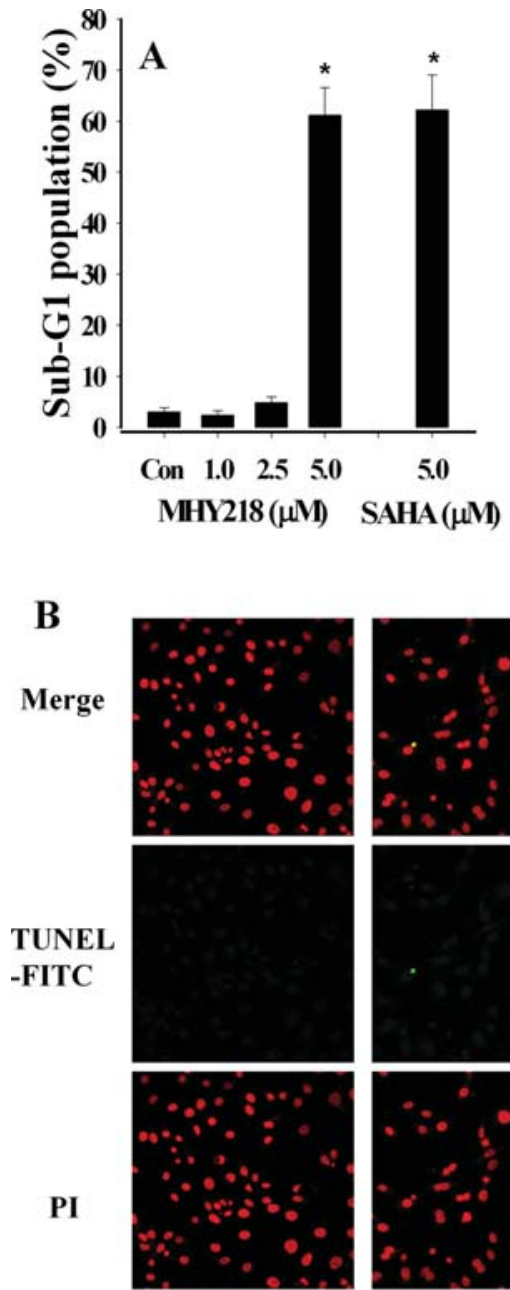

Con

MHY218
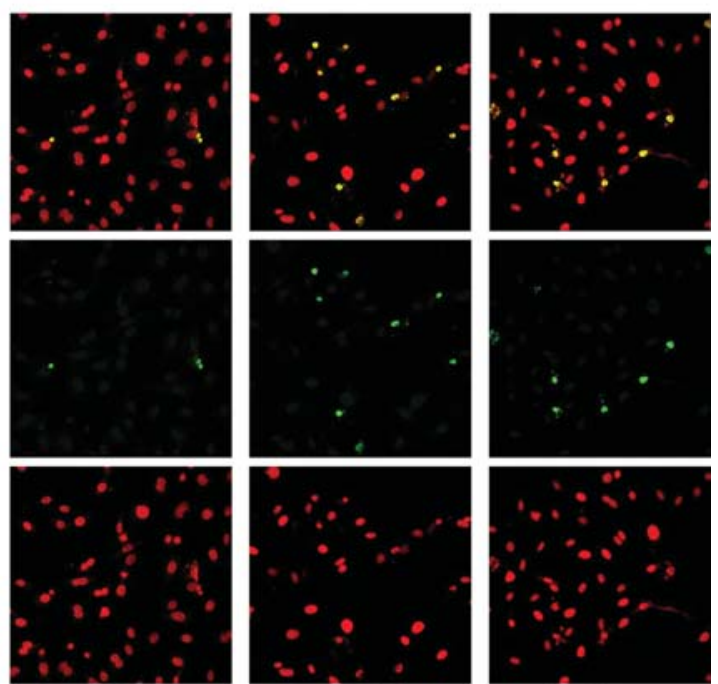

MHY218

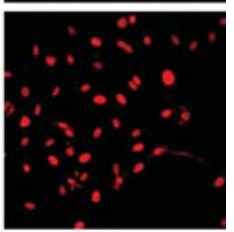

SAHA

$2.5 \mu \mathrm{M}$

$5.0 \mu \mathrm{M}$

$5.0 \mu \mathrm{M}$

Figure 5. Apoptosis analysis in SKOV-3 cells. (A) Apoptotic sub-G1 proportion by flow cytometry. Cells stained with propidium iodine (PI) and sub-G1 DNA contents were evaluated by flow cytometric analysis. (B) TUNEL assay for apoptotic cells. SKOV-3 cells were grown on coverslips at a density of $5 \times 10^{4}$ cells per well in a 24-well plate. After MHY218 and SAHA treatment, apoptosis was detected using an ApopTag fluorescein in situ apoptosis detection kit, and the cells were observed using confocal laser scanning. The magnification is x200. (C) Apoptotic cells numbers. The number of apoptotic cells were counted in ten random fields at $\times 200$ magnification and divided by the total number of cells per field. The data are reported as mean \pm SEM of two independent experiments. ${ }^{*} \mathrm{p}<0.05 ;{ }^{* *} \mathrm{p}<0.01$ as determined by ANOVA test.

that although neither agent showed a sizeable inhibition of cell proliferation at $24 \mathrm{~h}$ of treatment, morphologic changes were evident. As shown in Fig. 3B, SKOV-3 cells treated with $5 \mu \mathrm{M}$ MHY218 transformed the typical epithelial morphology to a more spindle-shaped morphology (middle). MHY218-treated cells seemed to be severely contracted with diminished cell-to-cell contacts and long spine-like processes. Similar morphologic changes were also observed in SKOV-3 cells treated with $5 \mu \mathrm{M}$ SAHA, although to a lesser extent (right). These findings indicate a clear effect of MHY218 treatment on SKOV-3 cells, preceding the observable effects on cell viability and/or apoptosis.

MHY218 increased the cellular proportion in the G2/M phase. The effect of MHY218 on the cell cycle progression of SKOV-3 cells was examined by flow cytometry analysis. SKOV-3 cells were treated with up to $5 \mu \mathrm{M}$ MHY218 for $48 \mathrm{~h}$, and MHY218 induced significant accumulation in the $\mathrm{G} 2 / \mathrm{M}$ phase of cell cycle and a concomitant decrease in the percentage of cells in the S phase (Fig. 4A). A total of $8 \%$ of the untreated SKOV-3 cells were in G2/M phase compared with $22.9 \%$ of cells cultured with $5 \mu \mathrm{M}$ MHY218. The effect of MHY218 on the expression of cell cycle-regulated proteins was further examined by Western blot analysis. As shown in Fig. 4B, MHY218 markedly increased the level of $\mathrm{p} 21^{\mathrm{WAF} 1 / \mathrm{CIP} 1}$ protein in a concentration-dependent manner. Therefore, MHY218 induced G2/M phase cell cycle arrest by increasing the level of $\mathrm{p} 21^{\mathrm{WAF} 1 / \mathrm{CIP} 1}$ protein.

Induction of apoptosis by MHY218 in SKOV-3 cells. We next assessed whether the growth inhibitory effect of MHY218 was related to the induction of apoptosis. As shown in Fig. 5A, an increase of sub-G1 population resulting from DNA fragmentation was observed in a concentrationdependent pattern. We used the Apotag (TUNEL) assay to confirm apoptotic cells by confocal microscopy. MHY 218 significantly increased the number of TUNEL-positive apoptotic cells compared with untreated control (Fig. 5B). As 

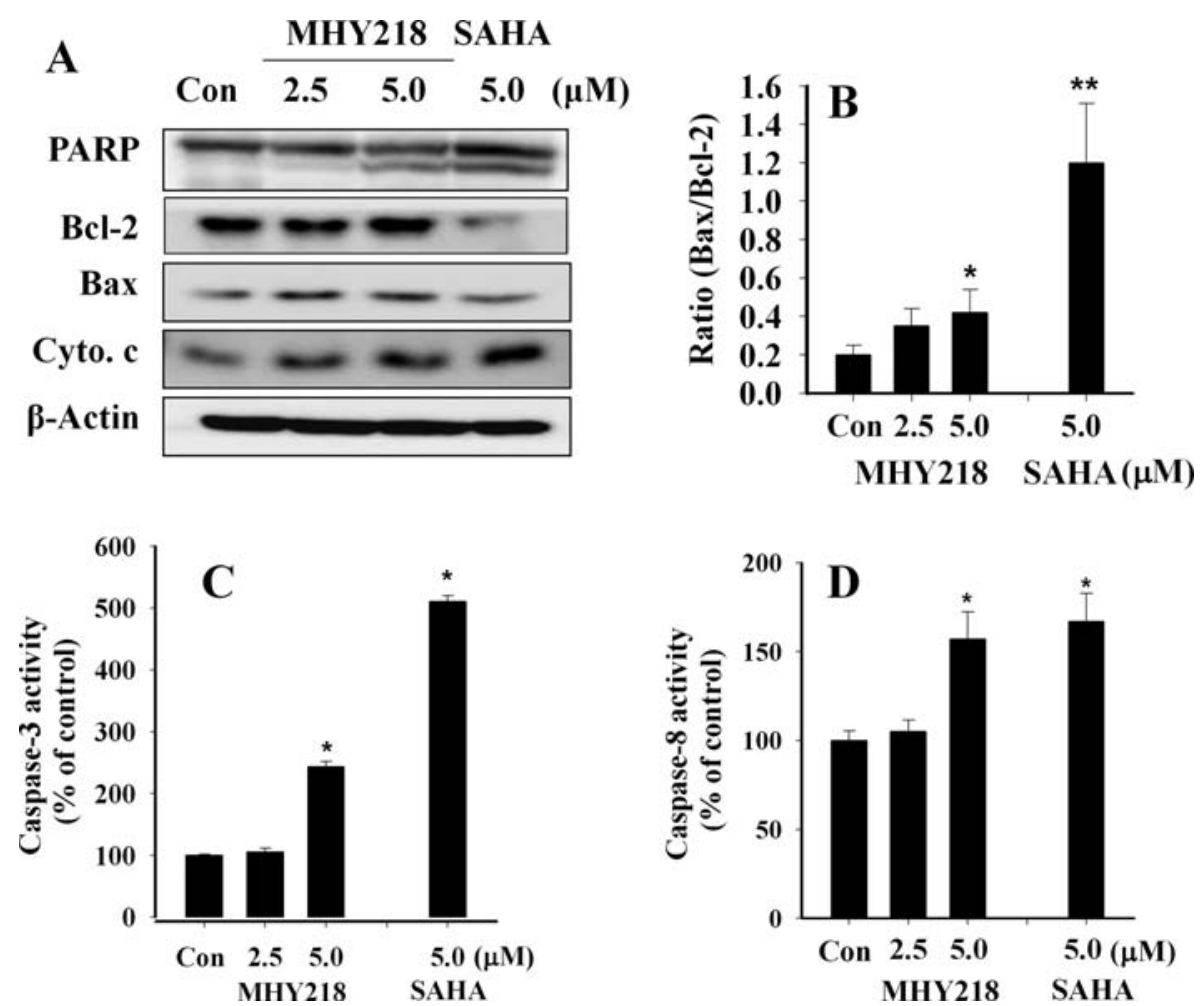

Figure 6. Effect of MHY218 on the apoptosis-related protein expression in SKOV-3 cells. (A) Immunoblot analysis of PARP, Bcl-2, Bax and cytochrome c protein levels. The SKOV-3 cells were treated with the indicated concentrations of MHY218 for $48 \mathrm{~h}$. Total cell lysates were prepared and subjected to SDSPAGE followed by Western blot analysis and chemiluminescent detection. Western blot analysis was performed using antibodies against PARP protein, Bcl-2, Bax and cytochrome c. Representative bands from three independent experiments are shown. (B) The ratio of Bax to Bcl-2 protein expression was determined from five separate experiments by comparing the relative intensities of protein bands. Data are presented as the mean \pm SEM values of Bcl-2/Bax ratio. ${ }^{*} \mathrm{p}<0.05 ;{ }^{* *} \mathrm{p}<0.01$ as determined by Student's t-test. (C) MHY218 activates caspase-3 in SKOV-3 cells. Cells were treated with the indicated concentrations of MHY218 for 48 h. Cytosolic extracts of cells were prepared, and caspase activity was determined using Colorimetric Assay Kit. Results represent the mean \pm SEM of two independent experiments. ${ }^{*} \mathrm{p}<0.05$ as determined by an ANOVA test difference compared with the control group.

shown in Fig. 5C, an increase of sub-G1 population resulting from apoptotic cells number was significantly increased in a concentration-dependent pattern. The expression of apoptosisrelated proteins was next examined. Treatment of SKOV-3 cells with MHY218 for $48 \mathrm{~h}$ induced marked cleavage of PARP (85 kDa), a known endogenous substrate for caspases, which are aspartate-specific cysteine proteases that play critical roles in apoptosis. Western blotting revealed that MHY218 induced cytoplasmic release of cytochrome $\mathrm{c}$ in SKOV-3 cells (Fig. 6A). The expression levels of the Bcl-2 family genes were measured to assess the apoptotic mechanism in cancer cells. MHY218 caused clear up-regulation of the pro-apoptotic gene, Bax (Fig. 6A). Densitometry analysis was next performed to determine the Bax/Bcl-2 ratio. MHY218 treatment is associated with concentration-dependent increases in the Bax/Bcl-2 ratio (Fig. 6B). Since PARP cleavage was observed in MHY218-treated cells, caspase-3 and -8 activities were next examined by using a chromogenic substrates specific to each of these enzymes. The activity of caspase- 3 was increased by $250 \%$ in $5.0 \mu \mathrm{M}$ MHY218treated cells compared with control (Fig. 6C). In addition, caspase- 8 activity also significantly increased in SKOV-3 cells by MHY218 treatment, but this activity was lower than caspase-3 activity (Fig. 6D). These data indicate that MHY218 induced apoptosis by activating caspase-3, which cleaved PARP.
Tumor burden in SKOV-3 cell carcinomatosis model. The effect of MHY218 on the growth of ovarian cancer cells in vivo was examined using an ovarian cancer cell carcinomatosis model as previously described $(22,23)$. The SKOV-3 cell-inoculated mice were administered with either MHY218 or vehicle twice a week for a 28-day period, and were sacrificed 30-day after cancer cell inoculation. At postmortem examination, the vehicle-treated controls had tumors in their entire peritoneal cavity, particularly on the surface of the peritoneum and intestines (Fig. 7A). However, MHY218 treated mice had much fewer disseminated tumors. Treatment of mice with MHY218 significantly reduced the tumor burden by $71 \%$ relative to the vehicle-treated controls (Fig. 7B). MHY218 did not affect the changes in body weight (data not shown). These results suggest that MHY218 has antitumor effects against SKOV-3 cells in vivo.

To confirm the histone acetylating effect of MHY218 treatment, the levels of acetylated $\mathrm{H} 3$ and $\mathrm{H} 4$ expression in SKOV-3 cell tumor tissue were measured by Western blot analysis. As shown in Fig. 7C, the tumors treated with MHY218 exhibited up-regulation of acetylated H3 and H4 expression compared to those in the vehicle-treated controls. The inhibitory effect of MHY218 on the specific HDAC isoforms in tumor tissue was next investigated. The levels of HDAC1, HDAC2 and HDAC4 expression were downregulated in the MHY218-treated tumor tissues. The relative 
A
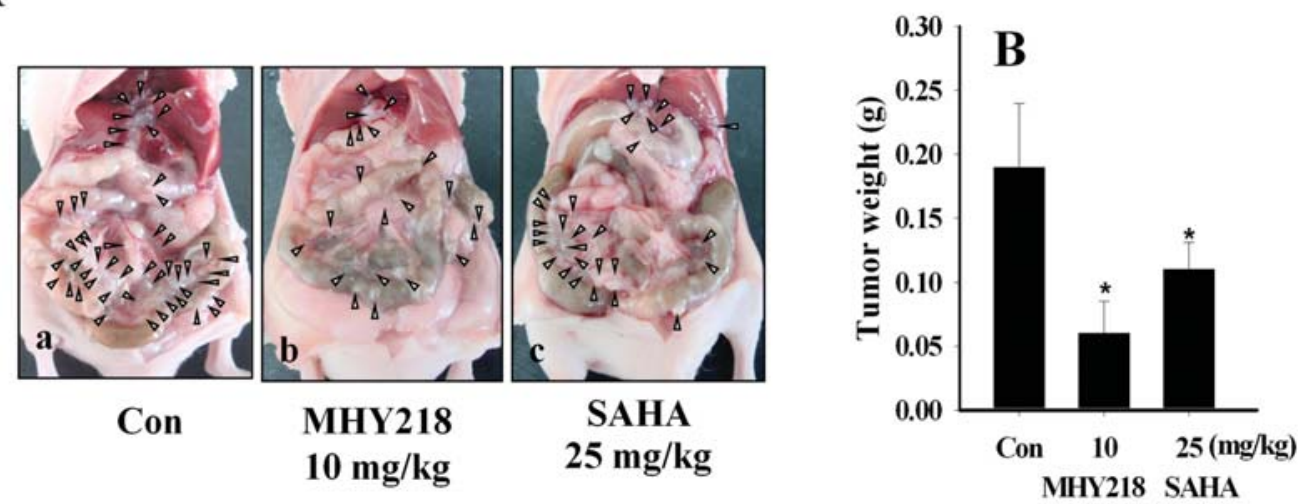
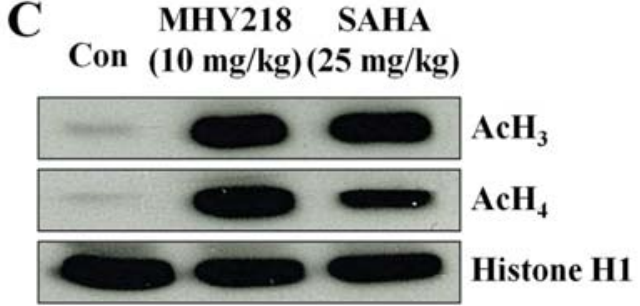

D
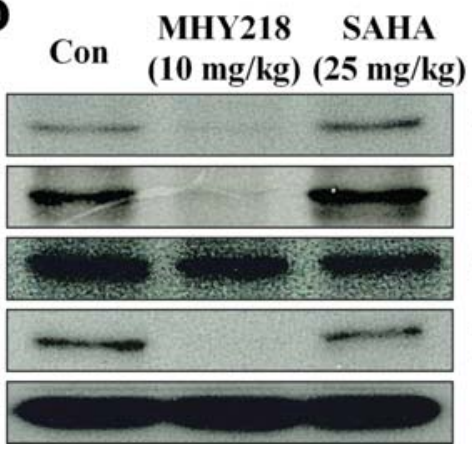

HDAC1

HDAC2

HDAC3

HDAC4

B-actin

Figure 7. Effect of MHY218 on intraperitoneal SKOV-3 cell tumor burden. (A) Athymic mice inoculated with SKOV-3 cells and (B) tumor burden weight. Representative athymic mice inoculated with SKOV-3 cells intraperitoneally (i.p.) treated with and without MHY218 and SAHA. a, vehicle-treated control mouse; b, MHY218-treated mouse; c, SAHA-treated mouse. Histological findings of the peritoneal cavities of mice treated with SAHA, MHY218 and the sham control. Arrows indicate the tumor. (B) The tumor burden weight data are reported as the mean \pm SEM of five animals. "p $<0.05$ as determined by a Student's t-test, compared with the control group. (C and D) Western blot analysis of acetylated H3, H4, and HDAC in the homogenates of three representative SKOV-3 tumors from each treatment group and their respective final volumes. The data are reported as the mean \pm SEM of three independent experiments.

expression levels of HDAC1 and HDAC4 were decreased 0.65 - and 0.59 -fold compared to those in the vehicle-treated controls, respectively (Fig. 7D). This shows that the inhibitory effect of tumor growth correlates with the inhibition of class I HDAC expression in vivo.

\section{Discussion}

HDAC is recognized as one of the promising targets for cancer treatment and many HDAC inhibitors have entered clinical trials for various types of human cancers $(6,24,25)$. In this study, the anticancer efficacy of MHY218 was examined against human ovarian cancer cells in vitro and in vivo. Our findings show that MHY218 exhibits a broad spectrum of antitumor activities at low submicromolar concentrations, including not only HDAC modulation but also the regulation of apoptotic cell death at multiple levels, such as cell cycle regulation and caspase activation. Furthermore, our findings show here that MHY218 is a potent inhibitor of ovarian cancer cell viability and induces a greater apoptotic response than SAHA.

MHY218 induced the accumulation of acetylated H3 and $\mathrm{H} 4$ proteins, which caused the transcriptional modulation of specific programmed genes and inhibited the activity of HDAC1, HDAC4 and HDAC7 in SKOV-3 cells. Most HDAC inhibitors do not selectively inhibit individual HDAC isoenzymes, but rather inhibit several HDACs simultaneously (26). The target specificity of these HDAC inhibitors remains unclear but it may be related to the significant overexpression of HDAC observed in cancer cells. Moreover, up-regulated expression of HDAC1 and HDAC2 has been demonstrated in human cancers $(27,28)$. HDAC4, HDAC8 and HDAC9 are more highly expressed to greater extent in tumor tissues and are specifically involved in differentiation $(29,30)$. It has been also reported that HDAC1 is highly expressed in prostate, gastric, colon and breast tumors (31) and HDAC6 acts as a downstream effector of estrogen signaling in breast cancer (25). However, the individual functions of the different isozymes on apoptotic cell death of the HDAC subfamily are unclear. Therefore, it is essential to identify the differences in HDAC functions to develop better target and tailor specific drugs $(25,32)$. Huang et al (33) found that SAHA ( $4 \mu \mathrm{M})$ resulted in $20 \%$ apoptotic nuclei at $48 \mathrm{~h}$ treatment. Additionally, cell cycle and apoptosis were reported to be associated with up-regulation of the cyclindependent kinase inhibitor $\mathrm{p} 21^{\mathrm{WAF} 1 / \mathrm{CIP} 1}$ via a p53-dependent mechanism. Our previous study demonstrated that MHY218, a novel hydroxamic acid-based HDAC inhibitor, possessed a potent antiproliferative activity against multiple cancer cell lines (unpublished data). However, there are no reports on the anticancer effects of MHY218 in human ovarian cancer cells. 


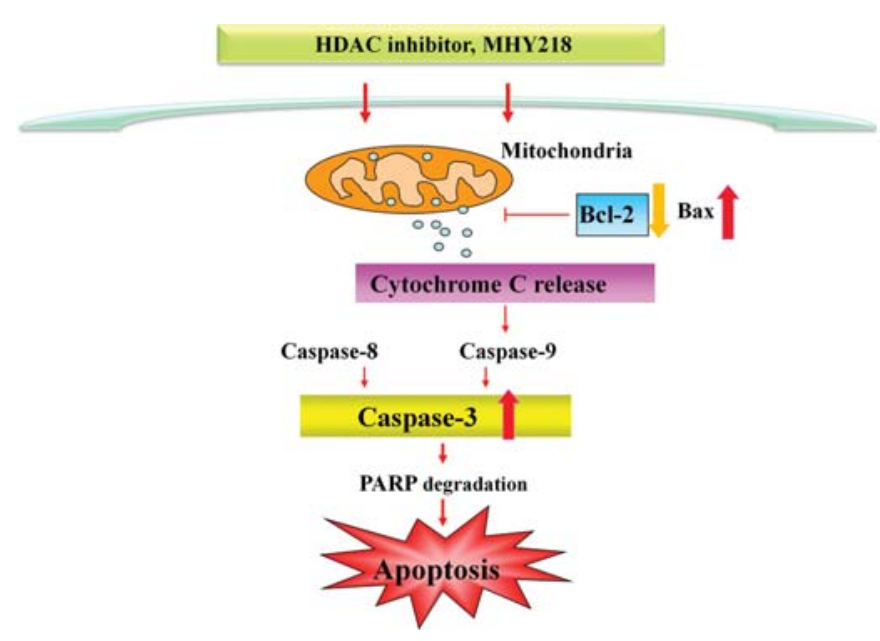

Figure 8. Probable molecular mechanism on the antitumor effect of MHY218. MHY218-induced cell cycle arrest was associated with an induction of p21 $1^{\mathrm{WAF} 1 / \mathrm{CIP} 1}$. MHY218 induces caspase-mediated apoptosis by cytochrome c release and Bcl-2 down-regulation. MHY218 increased the ratio of Bax/ Bcl-2 and increased the release of cytochrome c to cytosol. Up-regulation of caspase-3 was accompanied by the cleavage of PARP.

Increasing evidence shows that HDAC inhibitors decrease cancer cell proliferation by inducing cell cycle arrest in G1 and/or G2/M phase $(34,35)$. For example, SAHA induced G1 or $\mathrm{G} 2$ phase arrest in various cancer cells $(13,36,37)$. Consistent with these reports, MHY218 induced cell cycle arrest at G2/M phase in SKOV-3 cells, suggesting that MHY218 inhibited cell proliferation. Likewise, G2/M cell cycle arrest was also induced by SAHA in SKOV-3 cells. This may be associated with a decreased level of cyclin B1 as well as an increased $\mathrm{p} 21^{\mathrm{WAF} 1 / \mathrm{CIP} 1}$ expression. Although $\mathrm{p} 21^{\mathrm{WAF} 1 / \mathrm{CIP} 1}$ is commonly associated with the $\mathrm{G} 1$ check point, its association with G2/M cell cycle arrest has been also demonstrated (38). The sub-G1 population (late apoptotic cells) increased in the SKOV-3 cells cultured with SAHA and MHY218 compared with controls, suggesting that SAHA and MHY218 induced apoptosis.

It was reported that the $\mathrm{CDK}$ inhibitors, $\mathrm{p} 16^{\mathrm{INK} 4}, \mathrm{p} 21^{\mathrm{WAF} 1 / \mathrm{CIP} 1}$ and $\mathrm{p} 27^{\mathrm{KIP} 1}$, are important regulators of the cyclin/CDK complexes. Moreover, these genes are the target molecules most commonly induced by HDAC inhibitors, such as TsA, SAHA and apicidin (39-41). Recent studies have demonstrated that the HDAC inhibitor-mediated induction of $\mathrm{p} 21^{\mathrm{WAF} 1 / \mathrm{CIP} 1}$ is the result of increased $\mathrm{H} 3$ and $\mathrm{H} 4$ acetylation associated with the $\mathrm{p} 21^{\mathrm{WAF} 1 / \mathrm{CIP} 1}$ gene promoter $(42,43)$. Therefore, this study measured the levels of $\mathrm{p} 21^{\mathrm{WAF} 1 / \mathrm{CIP} 1}$ expression to examine the effect of MHY218 on the ovarian cancer cell cycle. The result suggests that MHY218 activates p $21^{\mathrm{WAF} 1 / \mathrm{CIP} 1}$ expression, leading to cell cycle arrest. These results are similar to a previous report showing that $\mathrm{p} 21^{\mathrm{WAF} 1 / \mathrm{CIP} 1}$ is one of the genes induced by various types of HDAC inhibitors $(41,43)$. The data indicate that MHY218 significantly increases the number of apoptotic cells, which may be associated with an increase in the levels of $\mathrm{p} 21^{\mathrm{WAF} 1 / \mathrm{CIP} 1}$ and cell cycle arrest at the G2/M phase. Bolden et al (26) reported that the treatment of endometrial cancer cells with HDAC inhibitors decreased the proportion of cells in the $\mathrm{S}$ phase and increased the proportion of cells in the G0/G1 and/or G2/M phases. Moreover, the level of cell cycle arrest correlated with the increase in $\mathrm{p} 21^{\mathrm{WAF} 1 / \mathrm{CIP} 1}$ expression. There is accumulating evidence suggesting that $\mathrm{p} 21^{\mathrm{WAF} 1 / \mathrm{CIP} 1}$ expression is closely related to the differentiation or apoptosis of cancer cells $(44,45)$, indicating its high potential as a target for cancer chemotherapy.

$\mathrm{Bcl}-2 / \mathrm{Bax}$ and caspase proteases are reportedly involved in regulating HDAC inhibitor-induced apoptosis $(22,46,47)$. Moreover, it was shown that apoptosis can be abrogated by overexpression of antiapoptotic Bcl-2, which is downregulated by HDAC inhibitors $(27,44)$. In this study, TUNEL assays were used to examine apoptotic cell death in order to determine the pathway triggered by MHY218. The assays revealed typical features of apoptosis in MHY218-treated SKOV-3 cells. The HDAC inhibitor-induced apoptotic pathways appear to be initiated by an internal, mitochondrial pathway. For example, the HDAC inhibitor sulforaphane down-regulates $\mathrm{Bcl}-2$, causes the release of cytochrome $\mathrm{c}$ from the mitochondria to the cytosol, and activates caspase-9, caspase- 3 and PARP cleavage (33).

Previous data show that caspase- 3 may be the key enzyme that mediates HDAC inhibitor-induced apoptosis $(25,29)$. The activation of caspase- 3 protease was accompanied by PARP (116 kDa) cleavage into an $85-\mathrm{kDa}$ C-terminal fragment and a $28-\mathrm{kDa} \mathrm{N}$-terminal fragment. These results showed increased caspase- 3 activation during apicidininduced apoptosis, which was confirmed by examining poly(ADP-ribose) polymerase (PARP), a known endogenous substrate for caspase-3. Furthermore, it was found that the expression of anti-apoptotic Bcl-2 is clearly down-regulated, while pro-apoptotic Bax expression is up-regulated. In addition, Bax and Bcl-2 may disrupt the mitochondrial membrane permeability and modulate the release of cytochrome $\mathrm{c}$. There is evidence suggesting that mitochondrial cytochrome $\mathrm{c}$ has dual functions in controlling both cellular energy metabolism and apoptosis. Once released from the mitochondria, cytochrome $\mathrm{c}$, which interacts with apoptotic protease-activating factors (Apaf), activates the execution of caspases that subsequently lead to apoptosis (29). Based on these results, the expression levels of Bcl-2 family genes were measured to determine the apoptotic pathway induced by MHY218 in SKOV-3 cells. Overall, MHY218 treatment significantly increased the $\mathrm{Bax} / \mathrm{Bcl}-2$ ratio in a concentrationdependent manner.

The therapeutic efficacy of HDAC inhibitors was tested in tumor xenograft models. Hydroxamic acid-type HDAC inhibitors reduced the tumor burden of experimental mammary, prostate, ovarian, colon and skin cancers $(28,29,45)$. Similar to previous studies, our data showed that MHY218 inhibits ovarian cancer tumor growth in an in vivo model. Compared with SAHA, MHY218 exhibited greater antiproliferative activity in human ovarian cancer cell lines in vitro. The greater potency of MHY218 to induce apoptosis, as evidenced by cytochrome c release, activation of caspase 3 and PARP cleavage, seemed to underlie this higher antitumor efficacy (Fig. 8). The correlation between the differential modulation of apoptotic signaling targets and in vitro antitumor activities of MHY218 and SAHA was mirrored in our in vivo study, in which MHY218 exhibited greater potency 
than SAHA in suppressing established SKOV-3 xenograft tumor growth.

In conclusion, these results show that the novel hydroxamic acid-derived HDAC inhibitor MHY218, is a potent inhibitor of HDAC that targets regulating multiple aspects of cancer cell survival including mitochondrial integrity and caspase activity. This broad spectrum of activity underlies the more potent apoptogenic and antitumor activities of MHY218 in vitro and in vivo relative to SAHA, and suggests its viability as part of a therapeutic strategy for ovarian cancer.

\section{Acknowledgements}

This study was supported by a grant of the Korea Healthcare technology R\&D Project, Ministry for Health, Welfare and Family Affairs, Republic of Korea (A084111).

\section{References}

1. Jemal A, Siegel R, Ward E, Hao Y, Xu J, Murray T and Thun MJ: Cancer Statistics. CA Cancer J Clin 58: 71-96, 2008.

2. Naora $\mathrm{H}$ and Montell DJ: Ovarian cancer metastasis: integrating insights from disparate model organisms. Nat Rev Cancer 5: 355-366, 2005.

3. Finnin MS, Donigian JR, Cohen A, Richon VM, Rifkind RA, Marks PA, Breslow R and Pavletich NP: Structures of a histone deacetylase homologue bound to the TSA and SAHA inhibitors. Nature 401: 188-193, 1999.

4. Mei S, Ho AD and Mahlknecht U: Role of histone deacetylase inhibitors in the treatment of cancer (Review). Int J Oncol 25: 1509-1519, 2004.

5. Sakimura R, Tanaka K, Nakatani F, Matsunobu T, Li X, Hanada M, Okada T, Nakamura T, Matsumoto Y and Iwamoto Y: Antitumor effects of histone deacetylase inhibitor on Ewing's family tumors. Int J Cancer 116: 784-792, 2005.

6. Pan LN, Lu J and Huang B: HDAC inhibitors: a potential new category of anti-tumor agents. Cell Mol Immun 4: 337-343, 2007.

7. Wade PA: Transcriptional control at regulatory checkpoint by histone deacetylase: molecular connections between cancer and chromatin. Hum Mol Genet 10: 693-698, 2001.

8. Feinberg AP, Ohlsson R and Henikoff S: The epigenetic progenitor origin of human cancer. Nature Rev 7: 21-33, 2006.

9. Glaser KB: HDAC inhibitors: Clinical update and mechanism based potential. Biochem Pharmacol 74: 659-671, 2007.

10. Kang MR, Kang JS, Han SB, Kim JH, Kim DM, Lee K, Lee CW, Lee KH, Lee CH, Han G, Kang JS, Kim HM and Park SK: A novel delta-lactam-based histone deacetylase inhibitor, KBHA42, induces cell cycle arrest and apoptosis in colon cancer cells. Biochem Pharmacol 78: 486-494, 2009.

11. Duvic M, Talpur R, Ni X, Zhang C, Hazarika P, Kelly C, Chiao JH, Reilly JF, Ricker JL, Richon VM and Frankel SR: Phase 2 trial of oral vorinostat (suberoylanilide hydroxamic acid, SAHA) for refractory cutaneous T-cell lymphoma (CTCL). Blood 109: 31-39, 2007.

12. Kuo PH, Carlson KR, Christensen I, Girardi M and Heald PW: FDG-PET/CT for the evaluation of response to therapy of cutaneous T-cell lymphoma to vorinostat (suberoylanilide hydroxamic acid, SAHA) in a phase II trial. Mol Imaging Biol 10: 306-314, 2008.

13. Butler LM, Agus DB, Scher HI, Higgins B, Rose A, CordonCardo C, Thaler HT, Rifkind RA, Marks PA and Richon VM: Suberoylanilide hydroxamic acid, an inhibitor of histone deacetylase, suppresses the growth of prostate cancer cells in vitro and in vivo. Cancer Res 60: 5165-5170, 2000.

14. Ruefli AA, Ausserlechner MJ, Bernhard D, Sutton VR, Tainton KM, Kofler R, Smyth MJ and Johnstone RW: The histone deacetylase inhibitor and chemotherapeutic agent suberoylanilide hydroxamic acid (SAHA) induces a cell-death pathway characterized by cleavage of Bid and production of reactive oxygen species. Proc Natl Acad Sci USA 98: 1083310838, 2001.

15. Marks PA: Discovery and development of SAHA as an anticancer agent. Oncogene 26: 1351-1356, 2007.
16. Qiu L, Kelso MJ, Hansen C, West ML, Fairlie DP and Parsons PG: Anti-tumour activity in vitro and in vivo of selective differentiating agents containing hydroxamate. Br J Cancer 80: 1252-1258, 1999.

17. Saito A, Yamashita T, Mariko Y, Nosaka Y, Tsuchiya K, Ando T, Suzuki T, Tsuruo T and Nakanishi O: A synthetic inhibitor of histone deacetylase, MS-27-275, with marked in vivo antitumor activity against human tumors. Proc Natl Acad Sci USA 96: 4592-4597, 1999.

18. Vigushin DM, Ali S, Pace PE, Mirsaidi N, Ito K, Adcock I and Coombes RC: Trichostatin A is a histone deacetylase inhibitor with potent antitumor activity against breast cancer in vivo. Clin Cancer Res 7: 971-976, 2001.

19. Jaboin J, Wild J, Hamidi H, Khanna C, Kim CJ, Robey R, Bates SE and Thiele CJ: MS-27-275, an inhibitor of histone deacetylase, has marked in vitro and in vivo antitumor activity against pediatric solid tumors. Cancer Res 62: 6108-6115, 2002.

20. Ahn MY, Lee J, Na YJ, Choi WS, Lee BM, Kang KW and Kim HS: Mechanism of apicidin-induced cell cycle arrest and apoptosis in Ishikawa human endometrial cancer cells. Chem Biol Interact 179: 169-177, 2009.

21. McGuire WP, Hoskins WJ, Brady MF, Kucera PR, Partridge EE, Look KY, Clarke-Pearson DL and Davidson M: Cyclophosphamide and cisplatin compared with paclitaxel and cisplatin in patients with stage III and stage IV ovarian cancer. N Engl J Med 334: 1-6, 1996.

22. Mabuchi S, Ohmichi M, Nishio Y, Hayasaka T, Kimura A, Ohta T, Saito M, Kawagoe J, Takahashi K, Yada-Hashimoto N, Sakata M, Motoyama T, Kurachi H, Tasaka K and Murata Y: Inhibition of NFkappaB increases the efficacy of cisplatin in vitro and in vivo ovarian cancer models. J Biol Chem 279: 23477-23485, 2004.

23. Hashimoto K, Morishige K, Sawada K, Tahara M, Kawagishi R, Ikebuchi Y, Sakata M, Tasaka K and Murata Y: Alendronate inhibits intraperitoneal dissemination in in vivo ovarian cancer model. Cancer Res 65: 540-545, 2005.

24. Acharya MR, Sparreboom A, Venitz J and Figg WD: Rational development of histone deacetylase inhibitors as anticancer agents: A review. Mol Pharmacol 68: 917-932, 2005.

25. Jung M: Inhibitors of histone deacetylase as new anticancer agents. Curr Med Chem 8: 1505-1511, 2001.

26. Bolden JE, Peart MJ and Johnstone RW: Anticancer activities of histone deacetylase inhibitors. Nat Rev Drug Discov 5: 769-784, 2006.

27. Zhu P, Martin E, Mengwasser J, Schlag P, Janssen KP and Gottlicher M: Induction of HDAC2 expression upon loss of APC in colorectal tumorigenesis. Cancer Cell 5: 455-463, 2004.

28. Huang BH, Laban M, Leung CH, Lee L, Lee CK, Salto-Tellez M, Raju GC and Hooi SC: Inhibition of histone deacetylase 2 increases apoptosis and $\mathrm{p} 21^{\mathrm{WAF} 1 / \mathrm{CIP} 1}$ expression, independent of histone deacetylase 1. Cell Death Differ 12: 395-404, 2005.

29. Grozinger CM and Schreiber SL: Deacetylase enzymes: biological functions and the use of small-molecule inhibitors. Chem Biol 9: 3-16, 2002.

30. de Ruijter AJ, van Gennip AH, Caron HN and Kemp S: Histone deacetylases (HDACs): characterization of the classical HDAC family. Biochem J 370: 737-749, 2003.

31. Nakagawa M, Oda Y, Eguchi T, Aishima S, Yao T, Hosoi F, Basaki Y, Ono M, Kuwano M, Tanaka M and Tsuneyoshi M: Expression profile of class I histone deacetylases in human cancer tissues. Oncol Rep 18: 769-774, 2007.

32. Miller TA, Witter DJ and Belvedere S: Histone deacetylase inhibitors. J Med Chem 46: 5097-5116, 2003.

33. Huang L and Pardee AB: Suberoylanilide hydroxamic acid as a potential therapeutic agent for human breast cancer treatment. Mol Med 6: 849-866, 2000.

34. Ungerstedt JS, Sowa Y, Xu WS, Shao Y, Dokmanovic M, Perez G, Ngo L, Holmgren A, Jiang X and Marks PA: Role of thioredoxin in the response of normal and transformed cells to histone deacetylase inhibitors. Proc Natl Acad Sci USA 102: 673-678, 2005.

35. Xu WS, Parmigiani RB and Marks PA: Histone deacetylase inhibitors: molecular mechanisms of action. Oncogene 26: 5541-5552, 2007.

36. Komatsu N, Kawamata N, Takeuchi S, Yin D, Chien W, Miller CW and Koeffler HP: SAHA, a HDAC inhibitor, has profound anti-growth activity against non-small cell lung cancer cells. Oncol Rep 15: 187-191, 2006. 
37. Fedier A, Dedes KJ, Imesch P, Von Bueren AO and Fink D: The histone deacetylase inhibitors suberoylanilide hydroxamic (Vorinostat) and valproic acid induce irreversible and MDR1independent resistance in human colon cancer cells. Int J Oncol 31: 633-641, 2007.

38. Niculescu AB, III, Chen X, Smeets M, Hengst L, Prives C and Reed SI: Effects of p $21^{\mathrm{WAF} / \mathrm{CIPl}}$ at both the G1/S and the G2/M cell cycle transitions: $\mathrm{pRb}$ is a critical determinant in blocking DNA replication and in preventing endoreduplication. Mol Cell Biol 18: 629-643, 1998.

39. Liotta LA: Tumor invasion and metastasis role of the extracellular matrix. Cancer Res 46: 1-7, 1986.

40. Kim JS, Lee S, Lee T, Lee YW and Trepel JB: Transcriptional activation of $\mathrm{p} 21^{\mathrm{WAF} / \mathrm{CIP} 1}$ by apicidin, a novel histone deacetylase inhibitor. Biochem Biophys Res Commun 281: 866-871, 2001.

41. Pulukuri SM, Gorantla B and Rao JS: Inhibition of histone deacetylase activity promotes invasion of human cancer cells through activation of urokinase plasminogen activator. J Biol Chem 282: 35594-35603, 2007.

42. Kim SH, Ahn S, Han JW, Lee HW, Lee HY, Lee YW, Kim MR, Kim KW, Kim WB and Hong S: Apicidin is a histone deacetylase inhibitor with anti-invasive and anti angiogenic potentials. Biochem Biophys Res Commun 315: 964-970, 2004.
43. Glozak MA and Seto E: Histone deacetylase and cancer. Oncogene 26: 5420-5432, 2007.

44. Pacheco MM, Mourao M, Mantovani EB, Nishimoto IN and Brentani MM: Expression of gelatinases A and B, stromelysin-3 and matrilysin genes in breast carcinomas: clinico-pathological correlations. Clin Exp Metastasis 16: 577-585, 1998.

45. Duffy MJ, Maguire TM, Hill A, McDermott E and O'Higgins N: Metalloproteinases: role in breast carcinogenesis, invasion and metastasis. Breast Cancer Res 2: 252-257, 2000.

46. Furumai R, Komatsu Y, Nishino N, Khochbin S, Yoshida M and Horinouchi S: Potent histone deacetylase inhibitors built from trichostatin A and cyclic tetrapeptide antibiotics including trapoxin. Proc Natl Acad Sci USA 98: 87-92, 2001.

47. Thangaraju M, Carswell KN, Prasad PD and Ganapathy V: Colon cancer cells maintain low levels of pyruvate to avoid cell death caused by inhibition of HDAC1/HDAC3. Biochem J 417: 379-389, 2009. 